\title{
TU/e EmonOWEN

\section{Evaluating an eco-olivine nanosilica as an alternative silica source in alkali-activated composites}

\section{Citation for published version (APA):}

Gao, X., Yu, Q., Lazaro Garcia, A., \& Brouwers, H. J. H. (2018). Evaluating an eco-olivine nanosilica as an alternative silica source in alkali-activated composites. Journal of Materials in Civil Engineering, 30(3), 1-8. [04018016]. https://doi.org/10.1061/(ASCE) MT.1943-5533.0002169

\section{Document license:}

TAVERNE

DOI:

10.1061/(ASCE) MT.1943-5533.0002169

Document status and date:

Published: 01/03/2018

\section{Document Version:}

Publisher's PDF, also known as Version of Record (includes final page, issue and volume numbers)

\section{Please check the document version of this publication:}

- A submitted manuscript is the version of the article upon submission and before peer-review. There can be important differences between the submitted version and the official published version of record. People interested in the research are advised to contact the author for the final version of the publication, or visit the $\mathrm{DOI}$ to the publisher's website.

- The final author version and the galley proof are versions of the publication after peer review.

- The final published version features the final layout of the paper including the volume, issue and page numbers.

Link to publication

\section{General rights}

Copyright and moral rights for the publications made accessible in the public portal are retained by the authors and/or other copyright owners and it is a condition of accessing publications that users recognise and abide by the legal requirements associated with these rights.

- Users may download and print one copy of any publication from the public portal for the purpose of private study or research.

- You may not further distribute the material or use it for any profit-making activity or commercial gain

- You may freely distribute the URL identifying the publication in the public portal.

If the publication is distributed under the terms of Article 25fa of the Dutch Copyright Act, indicated by the "Taverne" license above, please follow below link for the End User Agreement:

www.tue.nl/taverne

Take down policy

If you believe that this document breaches copyright please contact us at:

openaccess@tue.nl

providing details and we will investigate your claim. 


\title{
Evaluating an Eco-Olivine Nanosilica as an Alternative Silica Source in Alkali-Activated Composites
}

\author{
X. Gao'; Q. L. Yu²; A. Lazaro ${ }^{3}$; and H. J. H. Brouwers ${ }^{4}$
}

\begin{abstract}
In this study, an eco-olivine nanosilica is produced from natural olivine, and then used as an alternative silicate source in synthesizing the silicate-based alkali activator. The effects of silicate origin and dosage on activator characteristics, fresh behaviors, gel structure, strength, porosity, and shrinkage are investigated. The results indicate that the soluble silica content in the alternative activators is above 98\%; compared with the traditional waterglass-based mixes, the nanosilica-derived ones exhibit similar behaviors in the early age reaction, gel structure, and mechanical properties. As some important engineering properties, nanosilica-based mixtures also exhibit increased workability, prolonged setting time, slightly increased porosity, and shrinkage. Thus, by using this alternative silica source in alkali-activated materials, a more sustainable product with less cost and carbon emission can be achieved, and with comparable key performances. DOI: 10.1061/(ASCE) MT.1943-5533.0002169. ( 2018 American Society of Civil Engineers.
\end{abstract}

Author keywords: Olivine nanosilica; Alternative activator; Alkali activation; Slag-fly ash blends.

\section{Introduction}

In order to reduce the negative impacts of the cement industry in carbon emissions, consumption of natural raw materials, and high energy costs, great attention has been paid on applying alkaliactivated materials as alternatives to portland cement (Shi et al. 2011; Torgal et al. 2008; Gao et al. 2015a). This new type of binder material exhibits excellent mechanical properties, durability, and thermal resistance, in general (Provis et al. 2015; Shi et al. 2015; Huiskes et al. 2016; Fernandez et al. 2007), together with reduced energy costs and carbon emissions (Rashad 2013). The reaction products can be classified into two types depending on the input materials: C-A-S-H-type gels with high alumina content and relatively low calcium-to-silica ratios (Brough and Atkinson 2002); and N-A-S-H-type gel within three-dimensional zeolitelike networks (Li et al. 2010; Tennakoon et al. 2015). Besides, a mixed binder system that combines both types of gels raised research interests recently, because the stable coexistence of C-A-S-H- and $\mathrm{N}$-A-S-H-type gels results in several modified properties including the setting times, workability, shrinkage, mechanical properties, and durability (Lee and Lee 2013; Gao et al. 2016; Sugama

${ }^{1}$ Ph.D. Student, State Key Laboratory of Silicate Materials for Architectures, Wuhan Univ. of Technology, Wuhan 430070, P.R. China; Ph.D. Student, Dept. of Built Environment, Eindhoven Univ. of Technology, 5600 MB, Eindhoven, Netherlands. E-mail: x.gao@tue.nl

${ }^{2}$ Assistant Professor, Dept. of Built Environment, Eindhoven Univ. of Technology, $5600 \mathrm{MB}$, Eindhoven, Netherlands (corresponding author). ORCID: https://orcid.org/0000-0001-8578-3945. E-mail: q.yu@bwk.tue.nl

${ }^{3}$ Postdoctoral Researcher, Dept. of Built Environment, Eindhoven Univ. of Technology, $5600 \mathrm{MB}$, Eindhoven, Netherlands. E-mail: a.lazaro .garcia@tue.nl

${ }^{4}$ Professor, Dept. of Built Environment, Eindhoven Univ. of Technology, 5600 MB, Eindhoven, Netherlands; State Key Laboratory of Silicate Materials for Architectures, Wuhan Univ. of Technology, Wuhan 430070, P.R. China. E-mail: jos.brouwers@tue.nl

Note. This manuscript was submitted on November 28, 2016; approved on August 23, 2017; published online on January 9, 2018. Discussion period open until June 9, 2018; separate discussions must be submitted for individual papers. This paper is part of the Journal of Materials in Civil Engineering, (C) ASCE, ISSN 0899-1561. et al. 2005), and those improvements make this material competitive for applications.

The alkali activators play a dominating role in the reaction process; actually, any soluble substances that can supply alkali metal cations, increase the $\mathrm{pH}$ of the solution, and accelerate the dissolution of the solid raw materials can be used as activators. The commonly used ones are alkali hydroxides, silicates, carbonates, sulfates, aluminates, or oxides. Among these activators, it is widely accepted that silicate-based ones usually result in ideal mechanical properties with a much lower porosity (Shi 1996; Winnefeld et al. 2015; Wang et al. 1994; Puertas and Carrasco 2014) compared with other types of activators. This type of activator benefits the performances by offering alkaline conditions in a moderate and continuous manner; meanwhile, the additionally provided silicate from the activator will participate in the formation of reaction products and refine the microstructure (Duxson et al. 2005; Gao et al. 2015b).

However, although alkali-activated materials show an advantage over portland cement in sustainable development, the silicate-based activator still contributes a lot with respect to energy consumption and carbon emission in alkali-activated materials (Lellan et al. 2011). The production of sodium silicates includes the melting of sodium carbonate and quartz sand at high temperatures, over $1,000^{\circ} \mathrm{C}$, and this process results in a total carbon dioxide release of more than $400 \mathrm{~kg} / \mathrm{t}$ (European Commission 2007). Therefore, in order to pursue a more sustainable binder system, it is of great importance to develop activators with reduced environmental impacts while attaining high performances for the products. Efforts were made on producing alternative activators, such as the ones based on chemically modified nanosilica (Rodriguez et al. 2013), modified silica fume (Zivica 2006), industrial glass waste (Duxson et al. 2005), and silica fume or rice husk (Bernal et al. 2012). These alternative silicate-based activators could provide comparable mechanical properties and similar microscale characters compared with commercial sodium silicate-based ones. However, there are limited mechanism studies regarding the effect of alternative silicates as activator on the alkali-activated blended binder systems.

In this study, the feasibility of using an eco-olivine nanosilicabased activator in alkali-activated slag-fly ash blends is evaluated. This type of amorphous nanosilica can be produced by the 
dissolution of olivine, with extremely low environmental impact and low energy costs, and hence this exhibits potential as a sustainable silicate-based activator. The effect of olivine nanosilica on activator characteristics is investigated; the gel structure is investigated by using the Fourier transform infrared spectroscopy (FTIR). Important engineering and application-related properties of the products are studied and discussed, including flowability, setting times, mechanical properties, porosity, and drying shrinkage.

\section{Experiment}

\section{Materials}

A commercial ground granulated blast-furnace slag (GGBS, provided by ENCI, Netherlands) and Class F fly ash were used as input solids in this study. Their chemical compositions and particle size distributions (PSDs) are given in Table 1 and Fig. 1, respectively. A commercial sodium silicate solution $\left(27.69 \% \mathrm{SiO}_{2}, 8.39 \% \mathrm{Na}_{2} \mathrm{O}\right.$, and $63.92 \% \mathrm{H}_{2} \mathrm{O}$ by mass) and laboratory-prepared olivine nanosilica $\left(19.04 \% \mathrm{SiO}_{2}\right.$ and $80.96 \% \mathrm{H}_{2} \mathrm{O}$ by mass) were used as silicate sources of the alkaline activators, analytical levels of sodium

Table 1. Major Chemical Composition of GGBS and Fly Ash

\begin{tabular}{lrc}
\hline Oxides (\% by weight) & FA & GGBS \\
\hline $\mathrm{SiO}_{2}$ & 54.62 & 30.23 \\
$\mathrm{Al}_{2} \mathrm{O}_{3}$ & 24.42 & 12.58 \\
$\mathrm{CaO}$ & 4.44 & 40.51 \\
$\mathrm{MgO}$ & 1.43 & 9.05 \\
$\mathrm{Fe}_{2} \mathrm{O}_{3}$ & 7.21 & 0.60 \\
$\mathrm{Na}_{2} \mathrm{O}$ & 0.73 & - \\
$\mathrm{K}_{2} \mathrm{O}$ & 1.75 & 0.43 \\
$\mathrm{SO}_{3}$ & 0.46 & 3.47 \\
$\mathrm{LOI}$ & 2.80 & 1.94 \\
\hline
\end{tabular}

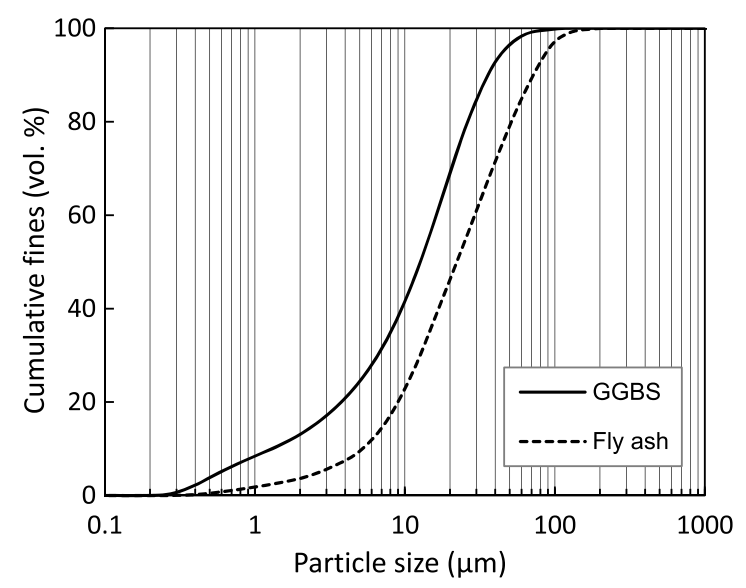

Fig. 1. Particle size distributions of raw materials hydroxide pellets were also applied to modify the activator. Activators with desired moduli were prepared by adding the appropriate amount of sodium hydroxide pellets into the silicate solution. The mixed activator solution was cooled down to room temperature prior to further use.

\section{Mix Design and Sample Preparation}

The activators used in this study had a sodium oxide content of $5 \%$ by mass of the binder, and the water:binder ratio was kept constant at 0.4 in all mixtures. The slag:fly ash mass ratio was fixed at 70:30. The binder:sand ratio was fixed at 1:3 for all mixes. Different levels of activator moduli within the commonly used range (from 2.0 to 0.8 ) were investigated for olivine nanosilica-based activators. Activators based on commercial waterglass were used as references to compare with olivine nanosilica-based ones. Detailed information of the mix proportions are listed in Table 2. Samples were prepared in a laboratory mixer; first the solid raw materials were added, followed by the activating solution. Then samples were cast and cured for 1 day, then demolded and cured at a temperature of $20^{\circ} \mathrm{C}$ and relative humidity of $95 \%$.

\section{Experiment}

The workability of mortar mixtures was tested according to European Committee for Standardization (CEN) 1015-3 (CEN 1999), and a free flow without jolting was allowed. The initial and final setting times were measured by a Vicat needle method as described in CEN 196-3 (CEN 2005b). Fourier transform infrared spectroscopy measurement was performed in a Varian 3100 instrument (Santa Clara, California) with the wavenumbers ranging from 4,000 to $600 \mathrm{~cm}^{-1}$ at a resolution of $1 \mathrm{~cm}^{-1}$. The compressive strength testing was carried out according to CEN 196-1 (CEN 2005a) at the ages of 7 and 28 days. The porosity was measured by applying the vacuum saturation technique following the description given in NT Build 492 (NT Build 1999). The water permeable porosity is calculated as

$$
P=\frac{M s-M d}{M s-M w} \times 100
$$

where $P=$ water permeable porosity $(\%) ; M s=$ mass of the saturated sample in surface-dry condition in air $(\mathrm{g}) ; M w=$ mass of water-saturated sample in water $(\mathrm{g})$; and $M d=$ mass of oven-dried sample (g).

Drying shrinkage tests were carried out using molds with dimensions $40 \times 40 \times 160 \mathrm{~mm}^{3}$ under conditions of $20^{\circ} \mathrm{C}$ and relative humidity of $50 \%$; the initial length $\left(L_{0}\right)$ was measured after $24 \mathrm{~h}$, then the length $\left(L_{n}\right)$ was measured once per day until the age of 28 days. The length change $(L, \%)$ was calculated as

$$
L=\frac{L_{0}-L_{n}}{L_{i}} \times 100
$$

where $L_{i}=$ effective initial length.

\begin{tabular}{|c|c|c|c|c|c|c|}
\hline \multicolumn{3}{|c|}{ Activator } & \multicolumn{3}{|c|}{ Solid raw materials $\left(\mathrm{g} / \mathrm{cm}^{3}\right)$} & \multirow[b]{2}{*}{$\mathrm{w} / \mathrm{b}$} \\
\hline Type & $\mathrm{Na}_{2} \mathrm{O}$ (by mass of the binder) $(\%)$ & $M s\left(\mathrm{SiO}_{2} / \mathrm{Na}_{2} \mathrm{O}\right)$ & Slag & Fly ash & Sand & \\
\hline \multirow[t]{2}{*}{ A: $\mathrm{WG}+\mathrm{NaOH}$} & 5 & 1.8 & 315 & 135 & 1,350 & 0.4 \\
\hline & 5 & 1.4 & 315 & 135 & 1,350 & 0.4 \\
\hline $\mathrm{B}: \mathrm{NS}+\mathrm{NaOH}$ & 5 & 1.0 & 315 & 135 & 1,350 & 0.4 \\
\hline
\end{tabular}

Table 2. Brief Description of Mix Proportions of Alkali-Activated Slag-Fly Ash Blend with Different Activators 

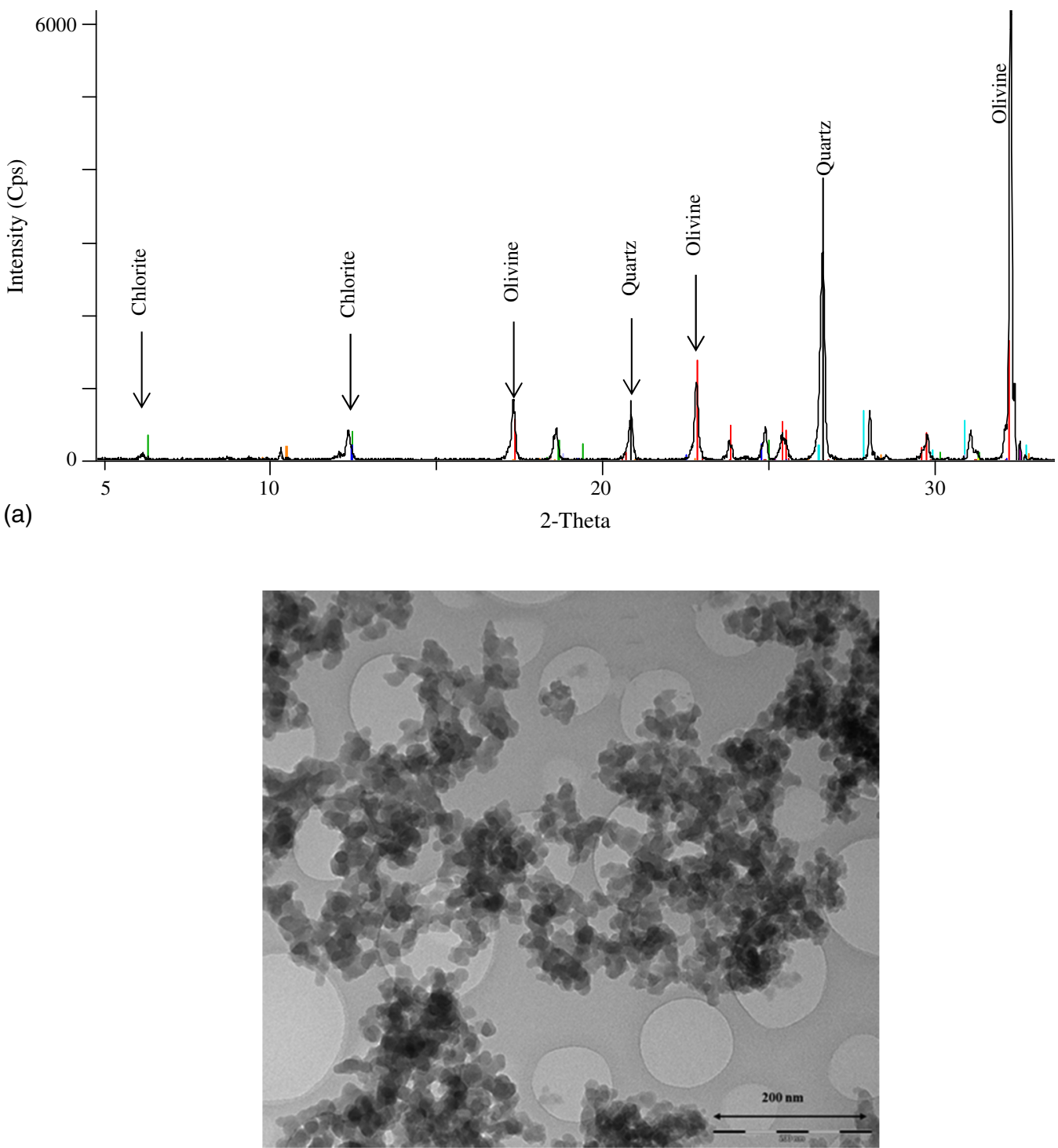

(b)

Fig. 2. (a) X-ray diffraction pattern of the produced olivine nanosilica (a $20 \%$ addition of quartz was added to the olivine to correct the diffractogram for the displacement and used as internal standard); (b) TEM image of produced olivine nanosilica

\section{Results and Discussion}

\section{Production of Olivine Nanosilica-Based Activator}

The production of this alternative activator consists of two steps, first the synthesis of olivine nanosilica, and then the dissolution of nanosilica in alkali solutions. The olivine nanosilica is produced by dissolving olivine mineral $\left[(\mathrm{Mg}, \mathrm{Fe})_{2} \mathrm{SiO}_{4}\right]$ in acid. Olivine is the most common silicate mineral in the upper mantle and a common mineral in the Earth's crust, which makes it low in price and widely applicable. In this study, amorphous silica was produced by mixing olivine stone with $3 \mathrm{M}$ sulfuric acid at $95^{\circ} \mathrm{C}$ for periods of time between 4 and $6 \mathrm{~h}$. The grounded olivine used had a particle size ranging between 100 and $500 \mu \mathrm{m}$ and a purity of $89 \%$ by weight. A chemical analysis is given in Lazaro et al. (2015) for sample GL50 with some other minor minerals present (i.e., micas, serpentine minerals, chlorite, talc, and enstatite) which are identified in the X-ray diffraction (XRD) in Fig. 2(a). After synthesis of silica, this material was cleaned by washing and filtering, and a filter cake product approximately $20 \%$ by weight of the solid content of nanosilica was then obtained. The produced olivine nanosilica had a specific surface area between 100 and $400 \mathrm{~m}^{2} / \mathrm{g}$, primary particles between 10 and $25 \mathrm{~nm}$, and silica content above 99\%. A typical transmission electron microscope (TEM) picture of the produced olivine nanosilica is shown in Fig. 2(b), nanoparticles with angular shape can be observed. Besides the low-temperature procedure, the process is exothermic with a reaction heat of $223 \mathrm{~kJ} / \mathrm{mol}$ of olivine (Jonckbloedt 1997).

Then, the olivine nanosilica-based activators were produced by mixing the laboratory-prepared nanosilica cake with sodium hydroxide pellets and distilled water to achieve target-activator moduli. Commercial sodium silicate-based activators were also designed to have the same chemical composition $\left(\mathrm{Na}_{2} \mathrm{O}-\mathrm{nSiO}_{2}-\mathrm{mH}_{2} \mathrm{O}\right)$ as references. The particle size distributions of the olivine nanosilica-based activator after filtering were measured, and the results show that the well dissolved in the activators with $M s$ from 0.8 to 2.0 (step of 0.2) are $99.84,99.88,99.75,99.73,99.35,98.08$, and 97.14\%, respectively, and no particles were found below $200 \mathrm{~nm}$ with the PSD measurement. Based on their ideal silica solubility and the commonly used activator moduli within the literature, three levels of 
activator modulus $(1.8,1.4$, and 1.0$)$ were chosen for the later performance evaluations.

\section{Advantages of Olivine Nanosilica in Sustainability}

It should be noted that in order to obtain commercial sodium silicate solution, the melting of quartz sand requires much higher temperature (usually over $1,000^{\circ} \mathrm{C}$ ) and, therefore, significantly higher energy costs and carbon emissions than the olivine nanosilica process that is performed at lower than $95^{\circ} \mathrm{C}$ (Lazaro 2014). An estimation of the cost of the raw materials, the energy requirements, and $\mathrm{CO}_{2}$ emissions is presented for both production processes. The average prices of dunite, sulfuric acid, sodium hydroxide, and waterglass with a $2.5 \mathrm{SiO}_{2}: \mathrm{Na}_{2} \mathrm{O}$ and silica content of $27 \%$ by weight are $\$ 152, \$ 113, \$ 400$, and $\$ 555 / \mathrm{t}$, respectively. The raw material cost of silica activator produced from the dissolution of olivine sums up to $\$ 1,148 / \mathrm{t}$ of silica equivalent, see Table 3 from Lazaro (2014). On the other hand, the price of commercial waterglass is almost twice as expensive as activators produced from olivine nanosilica, making it a total of $\$ 2,166 / \mathrm{t}$ of silica equivalent (Lazaro 2014; Jonckbloedt 1997).

In addition, $403 \mathrm{~kg}$ of $\mathrm{CO}_{2} / \mathrm{t}$ is released during the production of waterglass, the required energy reported by several companies for the production of 2.0 sodium silicate liquor $\left(\mathrm{SiO}_{2}: \mathrm{Na}_{2} \mathrm{O}\right.$ ratio of 2:1) with a $48 \%$ solid content (i.e., $32 \%$ by weight of $\mathrm{SiO}_{2}$ ) is between 420 and 1,250 MJ/t (European Commission 2007). Taking the average of these two values and considering that $3,900 \mathrm{~kg}$ of $27 \%$ by weight waterglass is used per silica ton results in an energy requirement of $2,800 \mathrm{MJ} / \mathrm{t}$. The energy required during the synthesis of olivine nanosilica could be negligible because the reaction is exothermic. Thus, the energy requirement as well as the $\mathrm{CO}_{2}$ emissions from the olivine nanosilica production process represents an enormous reduction as compared with the sodium silicate production process.

\section{Gel Structure}

The Fourier transform infrared spectroscopy has been extensively used in the characterization of the gel structure of alkali-activated materials. Fig. 3(a) shows the infrared spectra of two starting precursors: slag and fly ash. The original slag exhibits a main vibration band at around $900 \mathrm{~cm}^{-1}$, which is associated with the asymmetric stretching vibration of Si-O-T bonds (Rovnanik et al. 2013); a small absorption band at around $670 \mathrm{~cm}^{-1}$, is also shown in slag, which is assigned to the asymmetric stretching vibration of tetrahedral T-O groups (Kovalchuk et al. 2007). For the fly ash, absorption bands located at around 1,080, and 600 to $800 \mathrm{~cm}^{-1}$ indicate

Table 3. Estimated Costs of Sulfuric Acid, Olivine, and Sodium Hydroxide for the Production of $1 \mathrm{t}$ of Olivine Nanosilica

\begin{tabular}{lcc}
\hline Cost & Symbols & Amount \\
\hline Cost of acid & $n_{N S}(\mathrm{kmol})$ & 16.64 \\
& $n_{\mathrm{H} 2 \mathrm{SO} 4}(\mathrm{kmol})$ & 33.29 \\
& $m_{\mathrm{H} 2 \mathrm{SO} 4}(\mathrm{~kg})$ & 4,250 \\
& $C_{\mathrm{H} 2 \mathrm{SO} 4}(\$)$ & 645 \\
Cost of olivine & $n_{o l}(\mathrm{kmol})$ & 16.64 \\
& $m_{O l}(\mathrm{~kg})$ & 3,355 \\
Cost of $\mathrm{NaOH}$ & $C_{o l}(\$)$ & 377 \\
Overall cost & $m_{\mathrm{NaOH}}(\mathrm{kg})$ & 313 \\
& $C_{\mathrm{NaOH}}(\$)$ & 125 \\
\hline
\end{tabular}

the presence of small amount of quartz (Gadsden 1975) and the main vibration band is located at approximately $1,020 \mathrm{~cm}^{-1}$, showing a similar bond type as the slag ( $\mathrm{Si}-\mathrm{O}-\mathrm{T}$ bonds). The difference in the main band wavenumber is due to the different amorphous phase structure within the raw materials.

Fig. 3(b) presents the infrared spectra of all six mixes after 28 days of curing, where NS stands for nanosilica-based samples and WG represents waterglass-based samples. It is clear that after activation, all samples exhibit a main absorption band at around $960 \mathrm{~cm}^{-1}$, which is assigned to the asymmetric stretching vibration of the nonbridging Si-O bonds (Zhang et al. 2012). It indicates that the reaction product is dominated by chain structures, and they are generally regarded as $\mathrm{C}-\mathrm{A}-\mathrm{S}-\mathrm{H}-$ type gels. This $\mathrm{Si}-\mathrm{O}$ bond was originally located at around $900 \mathrm{~cm}^{-1}$ in the unreacted slag; an increase in wavenumber indicates a higher polymerized Si-O network. The absorption bands at around $1,400 \mathrm{~cm}^{-1}$ in all mixes correspond to the stretching vibrations of $\mathrm{O}-\mathrm{C}-\mathrm{O}$ in carbonates (Bernal et al. 2011), which suggests that a certain degree of carbonation occurred during the curing process. It can be noted that the typical reaction products (N-A-S-H-type gels) from alkali-activated fly ash that usually exhibit a bridge T-O-Si bond at around 1,000 to $1,100 \mathrm{~cm}^{-1}$ are not obviously observed in this study, revealing that the reaction products are a chain structure-dominated phase with relatively low polymerized degree. The presence of bound water is observed at approximately $1,650 \mathrm{~cm}^{-1}$ in all mixtures. As can be
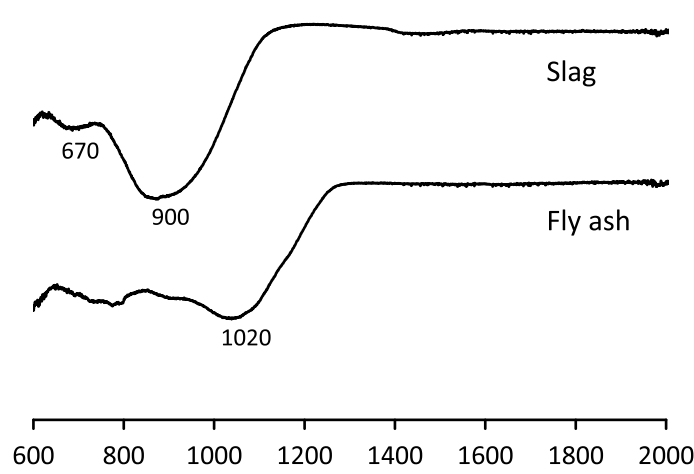

(a) Wavenumbers $\left(\mathrm{cm}^{-1}\right)$

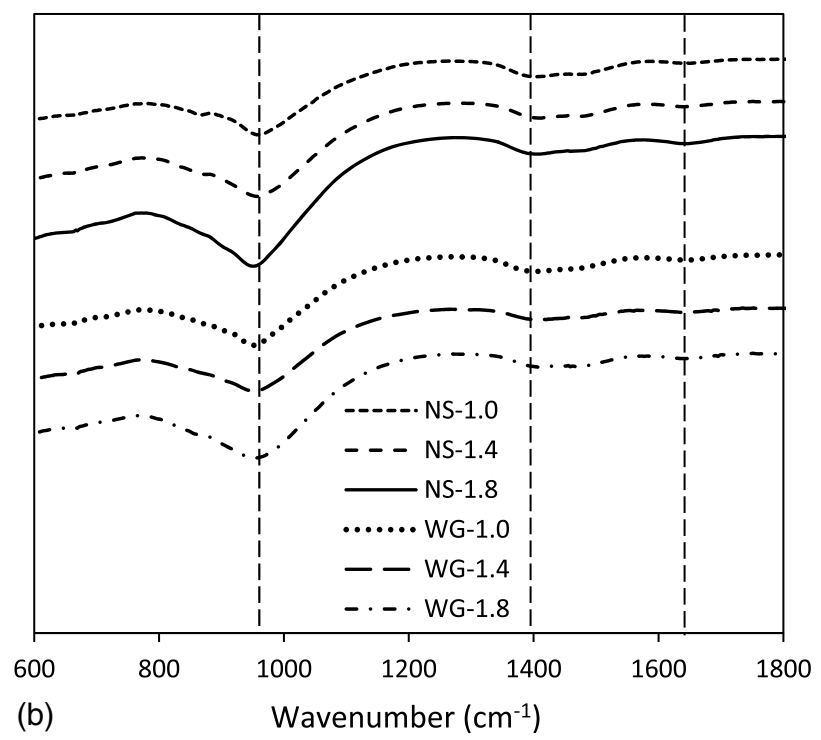

Fig. 3. (a) Fourier transform infrared spectroscopy spectra of input materials; (b) FTIR spectra of the reaction products 
noticed, the increase of activator modulus results in a slight shift of the main absorption band toward lower frequencies, and relatively high amplitude of the main absorption bands can be observed in mixes with a higher activator modulus, a reduced polymerization degree of the Si-O bonds and increased total amount of the terminal Si-O structure within the reaction products. The generally fixed positions of main absorption bands reveal that the gel structure of alkali activated slag-fly ash blends remains stable, whereas slight changes can be caused by the activator modulus, and compared with the commercial waterglass, the additional silicate provided by olivine nanosilica shows negligible effect on the gel characteristics.

\section{Workability and Setting Times}

The slump flows of the fresh alkali-activated slag-fly ash mortars with different activator type and modulus are presented in Fig. 4. It is clear that mixtures with olivine silica-based activators present a higher workability than the commercial sodium silicate-based ones, and samples with higher activator moduli exhibit higher flowability in general. For instance, with a constant activator modulus of 1.0, the slump flow is 15.6 and $17.7 \mathrm{~cm}$ for the waterglass and olivine silica-based activator, respectively. Similar results are also shown in mixes with other activator moduli. The relatively high workability due to the usage of nanosilica as alternative silicate source in the activator is also reported in a previous study silica (Rodriguez et al. 2013), where a chemically modified nanosilica was used. This can be explained by the silicate origin in the activator. In the case of commercial sodium silicate solutions, the higher the contents of available oligomers are in the solution, namely a lower modulus or higher $\mathrm{pH}$, the faster the reaction rate will be. Therefore, this leads to a reduced flowability by increasing the viscosity of the fresh paste.

The activator modulus also showed an obvious effect on the flowability, as can be seen from Fig. 4, that the slump flow increases from 17.7 to $23.5 \mathrm{~cm}$ (for nanosilica-based ones) when increasing the activator modulus from 1.0 to 1.8 . It is commonly known that an increased silicate content in the sodium silicate solution will result in an increase in the viscosity (Provis and Deventer 2009). Therefore, the mixture with a higher activator modulus

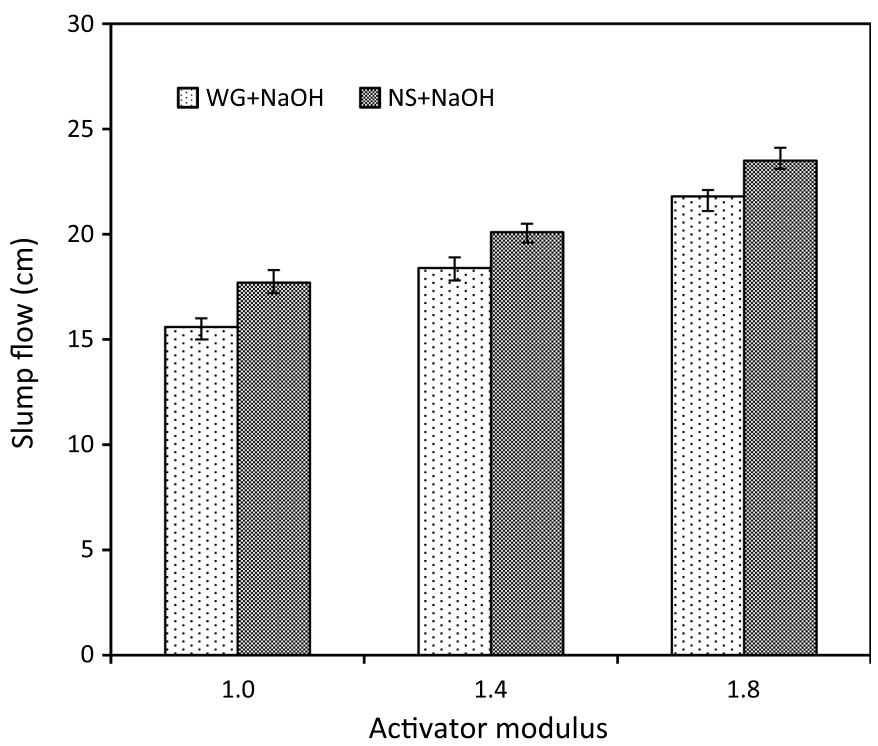

Fig. 4. Slump flows of alkali-activated slag-fly ash mortars with different activator conditions should exhibit a lower workability, whereas here the slump flow results were inversely related to the activator modulus. This phenomenon suggests that the chemical reaction between the solution and the raw materials plays a more significant influence on the flowability than the viscosity of the activating solution alone.

The initial and final setting times of all mixes are depicted in Fig. 5. It should be noted that for each column, lower values present the initial setting time and higher ones refer to the time of final setting. It can be seen that the nanosilica-based activators present longer setting times than the commercial sodium silicate-based ones, and mixtures with a lower activator modulus exhibit a faster setting time in general. For instance, the nanosilica-based mixes show an initial and final setting time of 22 and $63 \mathrm{~min}$, respectively, with an activator modulus of 1.0 , and it gradually prolongs to 55 and $99 \mathrm{~min}$, respectively, when the activator modulus increases to 1.8 .

\section{Compressive Strength}

The 7- and 28-day compressive strengths of mixtures with different activator moduli and silicate sources are depicted in Fig. 6. For each individual column, higher values refer to the 28-day strength whereas lower ones refer to the 7-day strength. All mixes show an increment in strength between the curing age of 7 and 28 days. For a fixed activator modulus, the olivine nanosilica-based samples exhibit rather comparable but slightly lower compressive strengths than the commercial sodium silicate-based ones. For instance, with an activator modulus of 1.0, the 7- and 28-day strength is 57.9 and $70.0 \mathrm{MPa}$, respectively, for the nanosilica-based ones, whereas for the sodium silicate-based mixes, this value is 64.7 and $75.4 \mathrm{MPa}$, respectively. A similar tendency is also shown in other activator moduli. Previous researches also indicate that samples synthesized by alternative silicate sources yield a lower strength than the traditional ones (Bernal et al. 2012). This phenomenon can be explained by the generally lower reaction degree of the input materials and therefore less-formed reacted gels results in a lower mechanical property (Ding et al. 2016; Shi and Day 1999). It should be noticed that although the olivine nanosilica-based mixes exhibit lower strengths, these values are in overall within $10 \%$ less than the corresponding sodium silicate-based ones. Their 7-day strengths range from 55.5 to $66.3 \mathrm{MPa}$ and the 28-day strengths are from 67.3 to $76.8 \mathrm{MPa}$, which are still suitable for various applications.

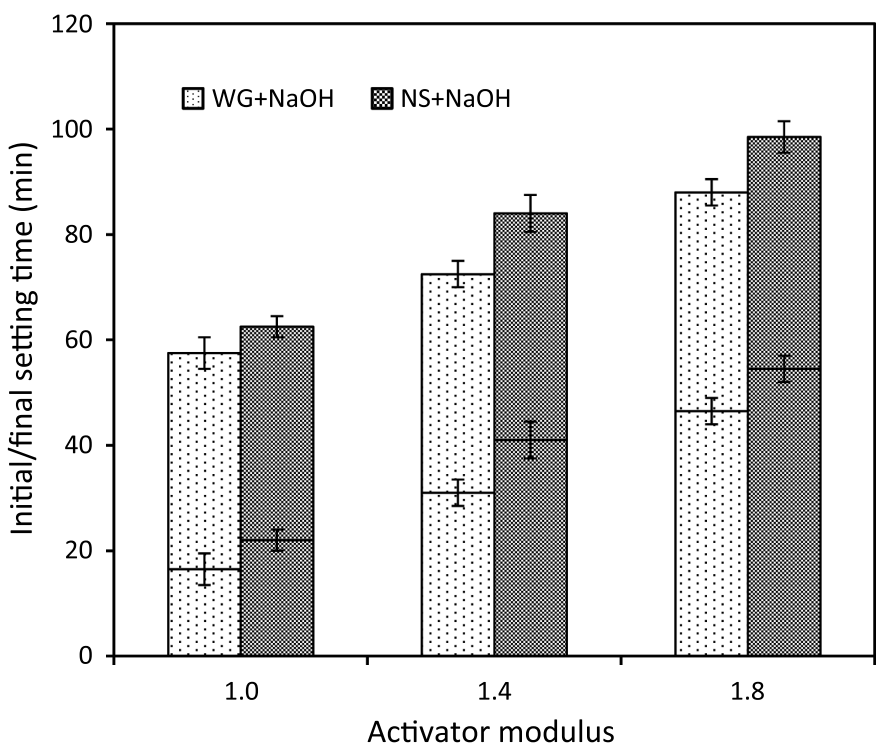

Fig. 5. Effect of activator conditions on setting times 


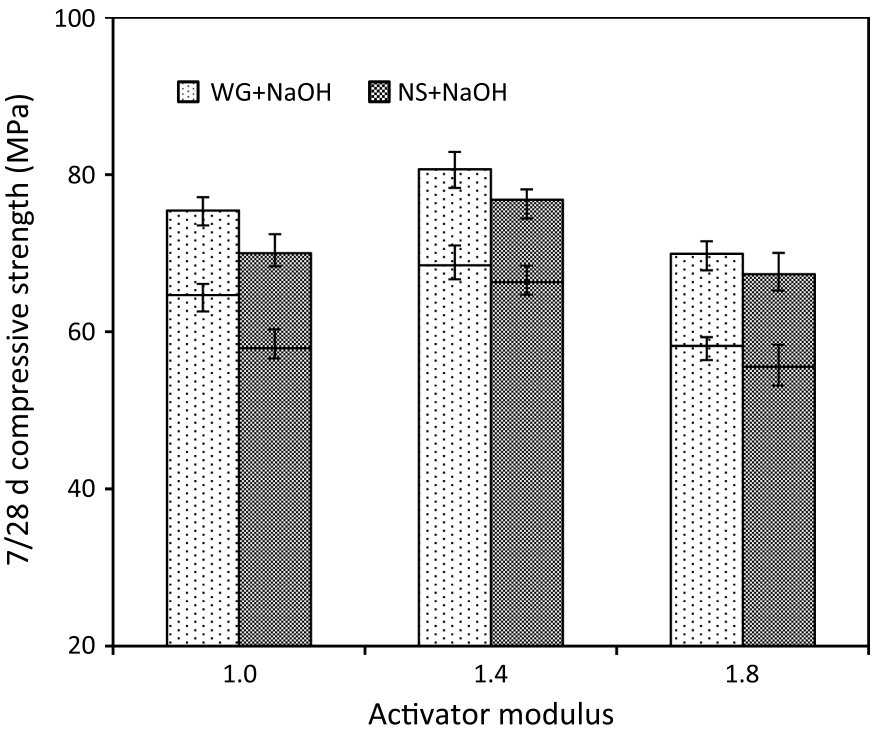

Fig. 6. Compressive strengths at 7 and 28 days of alkali activated slagfly ash blends with different activator conditions

It is well known that the activator modulus plays an important role in determining the compressive strength. The additional silicates from the activator participate in the reaction process and influence the $\mathrm{Si}: \mathrm{Ca}$ and $\mathrm{Si}: \mathrm{Al}$ ratios of the reaction products. The commonly used $\mathrm{Na}_{2} \mathrm{O}$ content for slag activation is around 3 to $6 \%$ by mass of the binder (Wang et al. 1994), whereas this value can be much higher in the case of alkali-activated aluminosilicates (Santaquiteria et al. 2012; Duxson et al. 2007; Silva et al. 2007). The used activator modulus is usually from 0 (only $\mathrm{NaOH}$ ) to around 2.0 (Wang et al. 1994; Shi et al. 2017). It is important to notice that in terms of the effective silicate content, a large amount is provided by the activator. For instance, the silicate provided by the activator consists of around 14 to $25 \%$ of the total silicate in this study. Therefore, an efficient utilization of the additional silicate or using alternative silicate source is of great interest in terms of the costs and the environmental issues of this material. It can be seen from Fig. 6 that for mixes based on olivine nanosilica, the 7-day strength is $57.9 \mathrm{MPa}$ with an activator modulus of 1.0 , and it increases to $66.3 \mathrm{MPa}$ when increasing the activator modulus to 1.4. A further increase of the modulus to 1.8 leads to a reduction of strength to $55.5 \mathrm{MPa}$. A similar tendency is also shown in the strength at 28 days, samples with an activator modulus of 1.4 exhibit the highest strength of $76.8 \mathrm{MPa}$. The presence of the optimal strength implies that there exists an optimum additional silicate content based on a certain composition of the input material. However, it is difficult to quantify this relation because several factors besides the total $\mathrm{Si}: \mathrm{Ca}$ and $\mathrm{Si}: \mathrm{Al}$ ratio also show an influence on compressive strength, such as the mineral composition, amorphous phase content and fineness of the input materials, alkali concentration, curing conditions, flowability, and porosity. On the other hand, changing the activator moduli from 1.0 to 1.8 leads to a strength variation up to $10.3 \mathrm{MPa}$, whereas besides the optimum strength, mixes with an activator modulus of 1.0 exhibit a slightly higher strength than the ones with modulus of 1.8. It is concluded that ideal compressive strengths can be achieved by using suitable content of additional silicate, because a further higher silicate content increases the cost and environmental impacts of the material but does not lead to an increased strength.

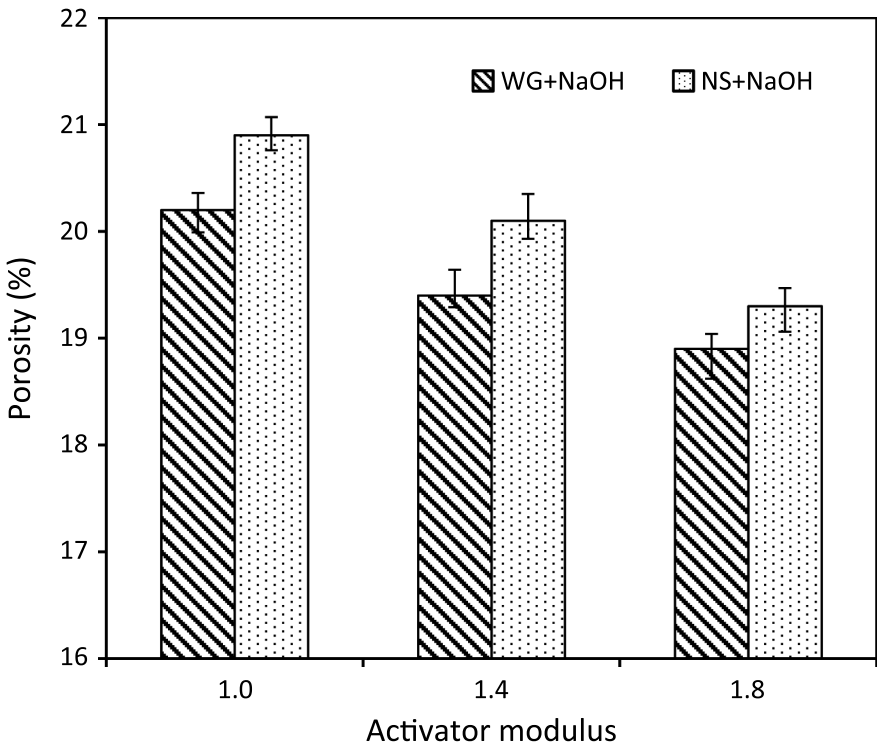

Fig. 7. Water permeable porosity at 28 days of mixes with different activator conditions

\section{Porosity}

The 28-day water-permeable porosities of all mixes are shown in Fig. 7. For the olivine nanosilica-based mixes, the porosity is $20.9 \%$ with an activator modulus of 1.0 , whereas it slightly decreases to $19.3 \%$ when increasing the modulus to 1.8. Similarly, the porosity of commercial sodium silicate-derived samples decreases from 20.2 to $18.9 \%$ within the activator modulus range. It is suggested that the gradual reduction of porosity is attributed to the additionally provided silicate groups from the activator, which refines the pore structure by both filler effect and participating in the resulted gels. Therefore, if porosity would be the only consideration, adding extra silicate within a reasonable range may always be beneficial. However, the relations between porosity and other properties shown in this study suggest a reasonable utilization of the additional silicates. For instance, the reduced porosity does not always result in an increased compressive strength, and an optimum activator modulus is shown in both cases. Regarding the effect of additional silicate source, it is easy to understand that commercial sodium silicate-based samples exhibit a comparable level of porosity, because these mixes present similar strength when compared with the olivine nanosilica-prepared ones.

\section{Drying Shrinkage}

The drying shrinkage of all mixtures until 28 days of curing is presented in Fig. 8. All mixes exhibit an obvious length change over time, and a higher drying shrinkage is usually shown when compared with the portland cement, owing to the nature of the reacted gels. It can be seen that both silicate source and activator modulus show a strong influence on the drying shrinkage. For instance, for the olivine nanosilica-based samples, the length change at the age of 28 days is around $-2,006 \times 10^{-6}$ for mixes with an activator modulus of 1.0 , whereas it decreases to $-2,803 \times$ $10^{-6}$ and $-3,868 \times 10^{-6}$ when increasing the activator modulus to 1.4 and 1.8, respectively. A similar tendency is also presented in commercial sodium silicate-based samples, where a reduced shrinkage is observed. For a constant fixed activator modulus, the alternative activator-based samples show a higher drying shrinkage around $400 \times 10^{-6}$, compared with the commercial 


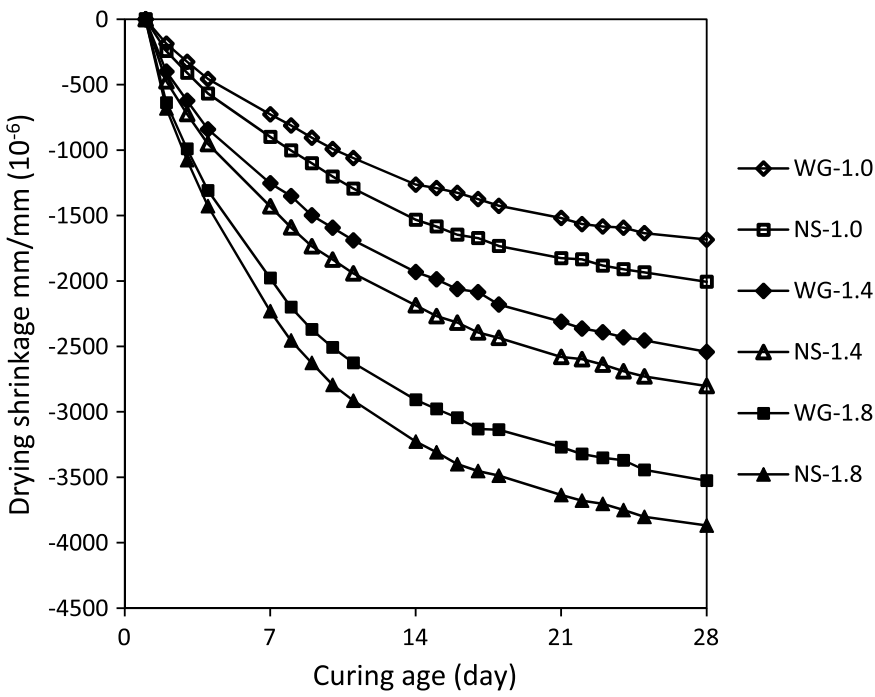

Fig. 8. Drying shrinkage of mixes with different activator conditions

waterglass-derived ones. The shrinkage results shown in this study are similar or even lower when compared with the previous investigations on the drying shrinkage of alkali-activated materials (Collins and Sanjayan 2000; Neto et al. 2008; Lee et al. 2014). Besides, a significant increase of drying shrinkage caused by the increased extra silicate content is also observed in another study of alkali-activated slag-fly ash blends (Ma and Ye 2015). It is possible that the refined pore structure caused by the additional silicate may be linked to the shrinkage behaviors due to the self-desiccation. Therefore, if the shrinkage is the main concern of a certain application, reducing the activator modulus can be an efficient approach.

\section{Conclusions}

A green olivine nanosilica was synthesized and applied as a silica source to produce an alternative alkali activator in alkaliactivated slag-fly ash blends. Mixes with three different contents of additional silica were designed. Performance evaluations were carried out including the activator characteristics, gel structure, compressive strength, porosity, and shrinkage. Comparisons were made with commercial sodium silicate-based mixes. The olivine nanosilica is well dissolved in $\mathrm{NaOH}$ solution to prepare activators with the same chemical composition of the sodium silicate-based ones. The soluble silicate in the nanosilica-based activators is above $99 \%$; except the one with a modulus of 1.8 , which, nevertheless, has a soluble silicate content of $98.1 \%$. Compared with the sodium silicate-based mixes, the nanosilica replacement results in an increased initial/final setting time, flowability, porosity, and shrinkage, and slightly reduced compressive strength. Nevertheless, the changes caused by the different silicate origin are rather limited. The investigation on the effect of activator modulus reveals modifications of the additional silicates from activator, and an optimum compressive strength is observed in mixes prepared with activator modulus of 1.4. The relations between the tested properties suggest the amount of additional provided silicate can be tailored on the basis of a certain application purpose. Therefore, it can be concluded that a green alternative activator can be produced by using olivine nanosilica with much lower costs and environmental impact while the performances remain in a similar level.

\section{Acknowledgments}

This research was supported by China Scholarship Council and the Department of the Built Environment at Eindhoven University of Technology. The authors gratefully thank Mr. P. de Vries (ENCI B.V., the Netherlands) for the materials supply. Furthermore, the authors wish to express their gratitude to the following sponsors of the Building Materials research group at TU Eindhoven: Rijkswaterstaat Grote Projecten en Onderhoud; Graniet-Import Benelux; Kijlstra Betonmortel; Struyk Verwo; Attero; Enci; Rijkswaterstaat Zee en Delta-District Noord; Van Gansewinkel Minerals; BTE; V.d. Bosch Beton; Selor; GMB; CRH Europe Sustainable Concrete Centre; Cement \& Beton Centrum; Heros; Inashco; Keim; Sirius International and Boskalis (in chronological order of joining).

\section{References}

Bernal, S. A., Provis, J. L., Rose, V., and Gutierrez, A. (2011). "Evolution of binder structure in sodium silicate-activated slag-metakaolin blends." Cem. Concr. Compos., 33(1), 46-54.

Bernal, S. A., Rodriguez, E. D., Gutierrez, R. M., Provis, J. L., and Delvasto, S. (2012). "Activation of metakaolin/slag blends using alkaline solutions based on chemically modified silica fume and rice husk ash." Waste Biomass. Valor., 3(1), 99-108.

Brough, A. R., and Atkinson, A. (2002). "Sodium silicate-based alkaliactivated slag mortars. I: Strength, hydration and microstructure." Cem. Concr. Res., 32(6), 865-879.

CEN (European Committee for Standardization). (1999). "Methods of test for mortar for masonry. 3: Determination of consistence of fresh mortar." CEN 1015-3, Brussels, Belgium.

CEN (European Committee for Standardization). (2005a). "Methods of testing cement. 1: Determination of strength." CEN 196-1, Brussels, Belgium.

CEN (European Committee for Standardization). (2005b). "Methods of testing cement. 3: Determination of setting times and soundness." CEN 196-3, Brussels, Belgium.

Collins, F., and Sanjayan, J. (2000). "Effect of pore size distribution on drying shrinking of alkali-activated slag concrete." Cem. Concr. Res., 30(9), 1401-1406.

Ding, Y., Dai, J. G., and Shi, C. J. (2016). "Mechanical properties of alkaliactivated concrete: A state-of-the-art review." Constr. Build. Mater., 127(30), 68-79.

Duxson, P., Mallicoat, S. W., Lukey, G. C., Kriven, W. M., and Deventer, J. S. J. (2007). "The effect of alkali and Si/Al ratio on the development of mechanical properties of metakaolin-based geopolymers." Colloids Surf. A., 292(1), 8-20.

Duxson, P., Provis, J. L., Lukey, G. C., Mallicoat, S. W., Kriven, W. M., and Deventer, J. S. J. (2005). "Understanding the relationship between geopolymer composition, microstructure and mechanical properties." Colloids Surf. A., 269(1-3), 47-58.

European Commission. (2007). Reference document on best available techniques for the manufacture of large volume inorganic chemicals: Solids and others industry, Brussels, Belgium.

Fernandez, A., Lodeiro, I., and Palomo, A. (2007). "Durable characteristics of alkali-activated fly ashes." J. Mater. Sci., 42(9), 3055-3065.

Gadsden, J. A. (1975). Infrared spectra of minerals and related inorganic compounds, Butterworths, London.

Gao, X., Yu, Q. L., and Brouwers, H. J. H. (2015a). "Characterization of alkali activated slag-fly ash blends containing nano-silica." Constr. Build. Mater., 98(15), 397-406.

Gao, X., Yu, Q. L., and Brouwers, H. J. H. (2015b). "Reaction kinetics, gel character and strength of ambient temperature cured alkali activated slag-fly ash blends." Constr. Build. Mater., 80(1), 105-115.

Gao, X., Yu, Q. L., and Brouwers, H. J. H. (2016). "Assessing the porosity and shrinkage of alkali activated slag-fly ash composites designed applying a packing model." Constr. Build. Mater., 119(30), 175-184. 
Huiskes, D. M. A., Keulen, A., Yu, Q. L., and Brouwers, H. J. H. (2016). "Design and performance evaluation of ultra-lightweight geopolymer concrete." Mater. Des., 89(5), 516-526.

Jonckbloedt, R. C. L. (1997). "The dissolution of olivine in acid, a cost effective process for the elimination of waste acids." Ph.D. thesis, Utrecht Univ., Utrecht, Netherlands.

Kovalchuk, G., Fernandez, A., and Palomo, A. (2007). "Alkali-activated fly ash: Effect of thermal curing conditions on mechanical and microstructural development. II." Fuel., 86(3), 315-322.

Lazaro, A. (2014). "Nano-silica production at low temperatures from the dissolution of olivine: Synthesis, tailoring and modeling." Ph.D. thesis, Eindhoven Univ. of Technology, Eindhoven, Netherlands.

Lazaro, A., Vegas, L. B., Brouwers, H. J. H., Geus, J. W., and Bastida, J. (2015). "The kinetics of the olivine dissolution under the extreme conditions of nano-silica production." Appl. Geochem., 52, 1-15.

Lee, N. K., Jang, J. G., and Lee, H. K. (2014). "Shrinkage characteristics of alkali-activated fly ash/slag paste and mortar at early age." Cem. Concr. Compos., 53, 239-248.

Lee, N. K., and Lee, H. K. (2013). "Setting and mechanical properties of alkali-activated fly ash/slag concrete manufactured at room temperature." Constr. Build. Mater., 47, 1201-1209.

Lellan, B. C., Williams, R. P., Lay, J., Riessen, A., and Corder, G. D. (2011). "Costs and carbon emissions for geopolymer pastes in comparison to ordinary portland cement." J. Clean. Prod., 19(9-10), 1080-1090.

Li, C., Sun, H. D., and Li, L. T. (2010). "A review: The comparison between alkali-activated slag $(\mathrm{Si}+\mathrm{Ca})$ and metakaolin ( $\mathrm{Si}+\mathrm{Al})$ cements." Cem. Concr. Res., 40(9), 1341-1349.

Ma, Y., and Ye, G. (2015). "The shrinkage of alkali activated fly ash." Cem. Concr. Res., 68, 75-82.

Neto, A. A., Cincotto, M. A., and Repette, W. (2008). "Drying and autogenous shrinkage of pastes and mortars with activated slag cement." Cem. Concr. Res., 38(4), 565-574.

NT Build. (1999). "Concrete, mortar and cement-based repair materials: Chloride migration coefficient from non-steady-state migration experiments." NT Build 492, Finland.

Provis, J. L., and Deventer, J. S. J. (2009). Geopolymers: Structure, processing, properties and industrial applications, Woodhead Publishing, Abingdon, U.K.

Provis, J. L., Palomo, A., and Shi, C. J. (2015). "Advances in understanding alkali-activated materials.” Cem. Concr. Res., 78, 110-125.

Puertas, F., and Carrasco, M. (2014). "Use of glass waste as an activator in the preparation of alkali-activated slag. Mechanical strength and paste characterization." Cem. Concr. Res., 57, 95-104.

Rashad, A. M. (2013). "A comprehensive overview about the influence of different additives on the properties of alkali-activated slag-A guide for Civil Engineer." Constr. Build. Mater., 47, 29-55.

Rodriguez, E. D., Bernal, S. A., Provis, J. L., Paya, J., Monzo, J. M., and Borrachero, M. V. (2013). "Effect of nanosilica-based activators on the performance of an alkali-activated fly ash binder." Cem. Concr. Compos., 35(1), 1-11.

Rovnanik, P., Bayer, P., and Rovnanikova, P. (2013). "Characterization of alkali activated slag paste after exposure to high temperatures." Constr. Build. Mater., 47, 1479-1487.

Santaquiteria, C., Skibsted, J., Fernandez, A., and Palomo, A. (2012). "Alkaline solution/binder ratio as a determining factor in the alkaline activation of aluminosilicates." Cem. Concr. Res., 42(9), 1242-1251.

Shi, C. (1996). "Strength, pore structure and permeability of alkaliactivated slag mortars." Cem. Concr. Res., 26(12), 1789-1799.

Shi, C. J., and Day, R. L. (1999). "Early strength development and hydration of alkali-activated blast furnace slag/fly ash blends." Adv. Cem. Res., 11(4), 189-196.

Shi, C. J., Fernandez, A., and Palomo, A. (2011). "New cements for the 21st century: The pursuit of an alternative to portland cement." Cem. Concr. Res., 41(7), 750-763.

Shi, C. J., Shi, Z. G., Hu, X., Zhao, R., and Chong, L. L. (2015). "A review on alkali-aggregate reactions in alkali-activated mortars/concretes made with alkali-reactive aggregates." Mater. Struct., 48(3), 621-628.

Shi, Z. G., Shi, C. J., Wan, S., and Ou, Z. H. (2017). "Effect of alkali dosage on alkali-silica reaction in sodium hydroxide activated slag mortars." Constr. Build. Mater., 143(7), 16-23.

Silva, P., Crenstil, K., and Sirivivatnanon, V. (2007). "Kinetics of geopolymerization: Role of $\mathrm{Al}_{2} \mathrm{O}_{3}$ and $\mathrm{SiO}_{2}$." Cem. Concr. Res., 37(4), $512-518$

Sugama, T., Brothers, L. E., and Putte, T. R. (2005). "Acid-resistant cements for geothermal wells: Sodium silicate activated slag/fly ash blends." Adv. Cem. Res., 17(2), 65-75.

Tennakoon, C., Silva, P. D., Crentsil, K., and Sanjayan, J. G. (2015). "Influence and role of feedstock $\mathrm{Si}$ and $\mathrm{Al}$ content in geopolymer synthesis." J. Sustainable Cem. Based Mater., 4(2), 129-139.

Torgal, F., Gomes, J., and Jalali, S. (2008). "Alkali-activated binders: A review. Part 1: Historical background, terminology, reaction mechanisms and hydration products." Constr. Build. Mater., 22(7), $1305-1314$.

Wang, S. D., Scrivener, K. L., and Pratt, P. L. (1994). "Factors affecting the strength of alkali-activated slag." Cem. Concr. Res., 24(6), 1033-1043.

Winnefeld, F., HaHa, M. B., Saout, G. L., Costoya, M., Ko, S. C., and Lothenbach, B. (2015). "Influence of slag composition on the hydration of alkali-activated slags.” J. Sustainable Cem.- Based Mater., 4(2), $74-84$.

Zhang, Z. H., Wang, H., Provis, J. L., Bullen, F., Reid, A., and Zhu, Y. C. (2012). "Quantitative kinetic and structural analysis of geopolymers. 1: The activation of metakaolin with sodium hydroxide." Therm. Acta., 539(10), 23-33.

Zivica, V. (2006). "Effectiveness of new silica fume alkali activator." Cem. Concr. Compos., 28(1), 21-25. 